\title{
VARIABILIDADE DE XANTHOMONAS MALVACEARUM (E. F. SMITH) DOWSON, NO ESTADO DE SÃO PAULO *
}

\author{
Edivaldo Cia ** \\ ERIC BALMER *** \\ Carlos A. M. Ferraz ** \\ I. L. GRIDI-PAPP ** \\ O. Paradela F。 ****
}

\begin{abstract}
RESUMO
No presente trabalho foi determinada a variabilidade de $\mathbf{x}$. malvacearum, em condições de casa de vegetação, baseando-se na reação dos hospedeiros diferenciais para raças fisiológicas do patógeno.

A técnica de inoculação empregada foi a de riscos feitos na página inferior das folhas e para avaliação dos sintomas foi adotada uma escala que variou de 1 a 5 .

Foi detectada a ocorrência das racas fisiológicas 3,8 e 10.

A linhagem do algodoeiro IAC RM3-4133 $71 / 523$ foi resistente raça fisiológica 3, enquanto que as linhagens (Acala x Nu.16) $71 / 213$ e IAC 12-2 $71 / 170$ foram resistentes às raças 3,8 e 10
\end{abstract}

\section{INTRODUÇAO}

A mancha angular do algodoeiro, causada por Xanthomonas malvacearum (E. F. Smith) Dowson, ocorre de forma generalizada em todas as regiões produtoras de algodão do Estado de São Paulo.

Embora os prejuízos econômicos não tenham sido avaliados, já foi relatodo por CIA e col. (1966) que a bacteriose pode destruir boa parte das folhas e maçãs do algodoeiro. $O$ conhecimento da variabilidade de $\mathbf{X}$. malvacearum, no tocante a patogenicidade, é de primordial importância para o melhoramento do algodoeiro, e, até o momento, não existem relatos sobre a ocorrência de raças fisiológicas no Estado de São Paulo. O principal objetivo deste trabalho foi estudar a variabilidade de $X$. malvacearum como também a reação de algumas variedades e linhagens de algodoeiro a este patógeno.

* Entregue para publicação em 28/12/73.

** Secção de Algodão - Instituto Agronômico do Estado de São Paulo, Bolsistas do Conselho Nacional de Pesquisas.

*** Departamento de Fitopatologia da Escola Superior de Agricultura "Luiz de Queizoz".

**** Secção de Microbiologia Fitotécnica - Instituto Agronômico do Estado de Săo Paulo Bolsista do Conselho Nacional de Pesquisas 


\section{REVISAO DA LITERATURA}

A variabilidade de $\mathbf{X}$. malvacearum foi estudada em diferentes partes do mundo, por vários pesquisadores, segundo trabalhos de HUNTER \& BLANK (1954), BRINKERHOFF (1959), 1963), BRODIE e COOPR (1960), SMITH (1962), NAYUDU (1964), MILLER (1938), CHEw e col. (1969), SCHNATHORST (1970) e VERMA e SING (1970).

Até o momento foram descritas dezessete raças fisiológicas de $\mathbf{X}$. malvacearum. $O$ início do estudo foi baseado na reação de três variedades de algodoeiro diferenciais, sendo elas Stoneville 2B (susceptível a todas as raças), Stoneville 20 (resistente à raça 1 susceptível à raça 2), e Mebane B-1 (resistente às raças 1 e 2). Utilizando-se destas três diferenciais os pesquisadores BRODIE e COOPER (1960), SCHNATHORST e col. (1960), SMITH (1962), BRINKERHOFF (1966) e CHEW e col. (1969) relataram a ocorrência das raças 1 e 2, juntas ou isoladamente numa mesma lavoura.

Em 1961, BIRD e col., citados por HUNTER e col. (1968), relataram a ocorrência de cinco raças fisiológicas baseados em reações de cinco linhagens de Gossypium hirsułum L.

BRINKERHOFF (1963) relatou a ocorrência de doze raças fisiológicas de.X. malvacearum, utilizando para isto cinco linhagens de $\mathbf{G}$. hirsutum e três linhagens de G. barbadense L. Posteriormente, HUNTER e col. (1968) relataram a ocorrência de quinze raças fisiológicas, baseados nas reações dos seguintes hospedeiros diferenciais: Acala 44, Stoneville 2B-S9, Stoneville 20, Mebane B-1, 1-10B, 20-3, 101-102B e Gregg. Por último, VERMA e SING (1970), utilizando estes mesmos hospedeiros, relataram a ocorrência de mais duas raças fisiológicas de $\mathbf{X}$. malvacearum, completando-se assim o total de dezessete raças, atualmente identificadas.

Paralelamente, dezesseis genes «B» ou maiores, assim denominados por KNIGHT, segundo BRINKERHOFF (1970), foram detectados no algodoeiro para resistência à $X$. malvacearum. Estes genes foram encontrados em diferentes espécies de algodoeiro, principalmente em G. hirsutum, G. barbadense, G. arboreum L.

Com relação ao comportamento de variedades cultivadas em condições de campo e em casa de vegetação em presença de $\mathbf{X}$. malvacearum, no Estado de São Paulo, foram poucos os trabalhos publicados. BASTOS CRUZ e col. (1965), estudando o comportamento de variedade de algodoeiro, concluiram que as variedades RM2, IAC 8 e IAC RM3 foram consideravelmente resistentes ao agente causador da mancha angular, enquanto que as variedades RM-1 e IAG $61 / 60$ foram mais susceptíveis.

CIA e col. (1966) estudaram o comportamento das variedades de algodoeiro Stoneville 20, Nu-16, Gregg, Mebane, RM-2 e IAC 12 em condições de casa de vegetação e das variedads Stoneville 20 , Nu-16, RM-4 e Rm-2 em condições de campo. Os dados revelaram que as variedades NU-16 e Stoneville 20, tanto em casa de vegetação com em condições de campo, foram resistentes, enquanto que as variedades Gregg, Mebane e IAC 12-2 em casa de vegetação e a variedade RM-4, em condições de campo, mostram-se susceptíveis 


\section{MATERIAIS E MÉTODOS}

Os isolados de $\mathbf{X}$. malvacearum foram obtidos de folhas de algodoeiro com lesões, provenientes de diferentes regiões do Estado de São Paulo.

Foram selecionados seis isolados de $\mathbf{X}$. malvacearum, para o estudo da variabilidade do patógeno no Estado de São Paulo, baseados em seis testes preliminares de patogenicidade. A inoculação do patógeno foi na página inferior dos cotilédones ou folhas novas de algodoeiro, através de ferimentos provocados por um palito previamente mergulhado numa suspensão bacteriana contendo aproximadamente $10^{8}$ talos bacterianos $/ \mathrm{ml}$. Para avaliação dos sintomas foi utilizado uma escala cujas notas variavam de 1 a 5 . A nota 1 foi atribuida ao risco sem encharcamento, seco, e a nota 5 ao risco mostrando lesões angulosas, verde oleosas maiores que $3 \mathrm{~mm}$. A identificação das raças fisiológicas foi baseada na reação apresentada pelos hospedeiros diferenciais reconhecidos pelo Cotton Disease Council. Considerou-se como resistente (-) o hospedeiro que apresentou nota média máxima até 1,9 e susceptível ( + o hospedeiro com a nota média acima de 3 . As linhagens cujas notas variavam de 2 a 2,9 foram consideradas de reações intermediárias (I) e para identificação das raças fisiológicas foram consideradas como de reação susceptível.

Foi feito um estudo da reação de algumas variedades e linhagens de algodoeiro à $X$. malvacearum, sendo utilizado o seguinte material da Secção de Algodão, do Instituto Agronômico: IAC RM3, IAC 13-1, IAC 12-2, IAC RM3 - 4133 71/523, IAC 12-2 71/170 e (Acala x Nu-16) 71/213.

Todos os trabalhos foram conduzidos em casa de vegetação onde a média da temperatura variou de 22 a $30^{\circ} \mathrm{C}$ e a umidade relativa do ar foi superior a $70 \%$.

\section{RESULTADOS E DISCUSSÃO}

As reações de resistência (-) ou susceptibilidade ( + ) dos hospedeiros diferenciais, aos isolados de $\mathbf{X}$. malvacearum são apresentadas no quadro 1 . 
Quadro 1 - Resistência (-) e susceptibilidade $(+)$ apresentada pclos hospedeiros diferenciais à inoculação de raças fisiológicas de $\underline{X}$. malvacearum.

HOSPEDEIROS DIFERENCIAIS E GENES DE RESISTENCIA

\begin{tabular}{|c|c|c|c|c|c|c|c|c|}
\hline $\begin{array}{c}\text { ISOLA- } \\
\text { DOS }\end{array}$ & $\begin{array}{c}\text { Ac. } 44 \\
\text { (nenhum) }\end{array}$ & $\begin{array}{c}\text { Ston. } \\
\text { 2B-S9 } \\
(\text { pol.*) }\end{array}$ & $\begin{array}{c}\text { Ston. } \\
20 \\
\left(\mathrm{~B}_{7}+\text { pol. }\right.\end{array}$ & $\begin{array}{l}\text { Mebane } \\
\mathrm{B}-1 \\
\left(\mathrm{~B}_{2}+\text { pol. }\right)\end{array}$ & $\left\{\begin{array}{l}1-10 \mathrm{~B} \\
\left(\mathrm{~B}_{\mathrm{In}}+\right. \\
\left.+ \text { pol. }^{+}\right)\end{array}\right.$ & $\begin{array}{r}20-3 \\
\left(\mathrm{~B}_{\mathrm{N}+}\right. \\
+ \text { pol. })\end{array}$ & $\left(\begin{array}{c}101- \\
102-\mathrm{B} \\
\left(\mathrm{B}_{2}+\mathrm{B}_{3}\right. \\
\left.+ \text { desc. }{ }^{* * *}\right)\end{array}\right.$ & RAÇA \\
\hline 40 & + & + & - & - & + & - & - & 3 \\
\hline 101 & + & + & - & - & + & - & - & 3 \\
\hline 118 & + & + & - & - & + & - & - & 3 \\
\hline 107 & + & + & + & + & + & - & - & 8 \\
\hline 115 & + & + & + & + & + & - & - & 8 \\
\hline 112 & + & + & + & + & + & + & - & 10 \\
\hline
\end{tabular}

Os resultados obtidos mostraram que os isolados 40,101 e 118 provocaram sintomas de susceptibilidade nos hospedeiros Acala 44, Stoneville 2B-S9 e $1-10 \mathrm{~B}$; os isolados 107 e 115 provocaram sintomas de susceptibilidade nos hospedeiros Acala 44, Stoneville 2B-S9, Stoneville 20, Mebane B-1 e 1-10B enquanto que o isolado 112 só não foi patógenico no hospedeiro 101-102B.

Quando comparados os resultados conseguidos no ensaio com aqueles descritos por BRINKERHOFF (1970), pode-se concluir que no Estado de São Pdulo, ocorrem as raças fisiológicas 3,8 e 10 de $X$. malvacearum.

Não foi possível determinar a distribuição das raças pelas diferentes regiões algodoeiras paulistas, o que seria de grande interesse para o melhoramento do algodoeiro. A detecção da raça 10 em nosso meio é de suma importância. Convém salientar que as linhagens diferenciais somente a 101 $102 \mathrm{~B}$, possuidora dos genes $\mathrm{B}_{2} \mathrm{~B}_{3}+$, é resistente a essa raça de bactéria. Este fato evidencia a necessidade de serem esquematizados programas de melhoramento do algodoeiro, visando a introdução dos genes $B_{2} B_{3}$ nas variedades a serem distribuidas, evitando-se no futuro possíveis problemas de ordem econômica. Deixa de ter interesse a introdução do gene $B_{7}$ nas variedades paulistas de algodoeiro, uma vez que já ocorrem no Estado de São Paulo raças fisiológicas de $\mathbf{X}$. malvacearum que provocam reações de susceptibilidade em material contendo o gene $B_{7}$.

As reações de resistência e susceptibilidade apresentadas pelas variedades e linhagens testadas do Instituto Agronômico são apresentadas no quadro 2. 
Quadro 2 - Resistencia (-) e susceptibulidade $(+)$ apresentada pelas variedades e linha. gens IAC aOs isoladios de $\underline{X}$. malvacearum.

VARIEDADES E LINHAGENS

\begin{tabular}{c|c|c|c|c|c|c|c}
\hline $\begin{array}{c}\text { ISOLA- } \\
\text { DUS }\end{array}$ & RAÇA & IAC RM & $\begin{array}{c}\text { IAC } \\
13-1\end{array}$ & $\begin{array}{c}\text { IAC } \\
12-2\end{array}$ & $\begin{array}{c}\text { IAC RM } \\
-4133 \\
71 / 523\end{array}$ & $\begin{array}{c}\text { IAC } \\
12-2 \\
71 / 170\end{array}$ & $\begin{array}{c}\text { (Acala } \\
\times \text { Nu-16) } \\
71 / 213\end{array}$ \\
\hline 101 & 3 & + & + & + & - & - & - \\
107 & 8 & + & + & + & + & - & - \\
112 & 8 & + & + & + & + & - & - \\
115 & 10 & + & + & + & + & - & - \\
\hline
\end{tabular}

Os resultados mostraram que a linhagem IAC RM3-4133 71/523 foi resistente à raça 3 , enquanto que as linhagens IAC 12-2 71/170 e (Acala x Nu-16) $71 / 213$ foram resistentes às raças 3,8 e 10. Estas duas últimas linhagens são de grande interesse para os programas de melhoramento visando o controle da mancha angular do algodoeiro, uma vez que apresentam fontes de resistência, no mínimo, para três raças fisiológicas. De maneira geral, comparandose os resultados, foi verificado que as linhagens IAC RM3 e IAC 12-2, apresentaram reações de resistência não encontradas nas variedades originais. Este fato mostra a existência de variabilidade nas populações de hospedeiro, para diferentes raças fisiológicas de $\mathbf{X}$. malvacearum.

As variedades IAC RM3, IAC 13-1 e IAC 12-2 apresentaram reações semelhantes de susceptibilidade aos quatro isolados testados.

\section{CONCLUSOES}

Do presente trabalho pode ser concluido:

1. Foram identificadas, no Estado de São Paulo, as raças fisiológicas de X. malvacearum 3,8 e 10, baseando-se nas reações dos hospedeiros diferenciais reconhecidos pelo Cotton Disease Council.

2. A linhagem de algodoeiro IAC RM3 - $413371 / 523$ foi resistente a raça fisiológica 3, enquanto que as linhagens IAC 12-2 71/170 e (Acala $x$ $\mathrm{Nu}$-16) 71/213 foram resistentes às raças fisiológicas 3,8 e 10 .

3. As variedades IAC RM3, IAC 12-2 e IAC 13-1, apresentaram reação semelhante de susceptibilidade às raças fisiológicas 3,8 e 10.

\section{SUMMARY}

PHYSIOLOGIC RACES OF X. MALVACEARUM (E. F. SMITH) DOWSON IN THE STATE OF SÃO PAULO.

The variability of $\mathbf{X}$. malvacearum was studied under greenhouse condi- 
tions with isolates obtained from the principal cotton growing regions of the State of São Paulo.

The isolates were introduced into the tissues by scratching the under side of the leaves with a bamboo pick previously dipped in a bacterial suspension. For the evaluation of the symptoms a scale based on five infection types was used.

As a result of these tests, the isolates were grouped into three races of $X$. malvacearum respectively races 3,8 and 10 .

The IAC RM3 71/523 line showed resistence to race 3 , while (Acala $\mathbf{x}$ $\mathrm{Nu}-16$ ) $71 / 213$ and IAC 12-2 71/170 lines showed resistence to races 3,8 and 10.

The susceptible cotton varieties IAC RM3, IAC 13-1 and IAC 12-2, cultivated in São Paulo State, reacted equally to the thrce races mentioned.

\section{LITERATURA CITADA}

BASTOS CRUZ, B. P., SILVEIRA, A. P., ABRAHÃO, J. \& SILVEIRA, S. G. P. - Observações relativas a resistência de algumas variedades de algodoeiro ao ataque da "mancha angular" (Xanthomonas malvacearum) (E. F. Smith) Dow. Ar. Inst. biol. São Paulo 32: 45-51, 1965.

BRINKERHOFF, L. A. Variability for pathogenicity of Xanthomonas malvacearum Phytopathology 49 (9): 534, 1959 (Abstract).

Pl. Dis. Report. 50: 323-324, 1966.

control An. Rev. Phytopath. 8: 85-110, 1970.

BRODIE, B. P. \& COOPER. W. E. Reaction of diferential cotton varieties to isolates of Xanthomonas malvacearum in North Carolina. Pl. Dis. Reptr. 44: 800-801, 1960 .

CIA; E. SALGADO, C.; CONTI, E. de \& BALMER E. Reaçōes fisiológicas de resistência à Xanthomonas malvacearum. (E. F. Smith) Drow.. em algumas variedades de algodão. Anais Esc. Sup. Agric. "Luiz de Queiroz" 23: 265-271, 1966.

CHEW, C. F.; PRESLEY, J. T. \& STATES, G. Survey, Screening and breeding for bacterial bligth resistence in cotton. Plt. Dis. Reptr. 53: 390-391, 1969.

HUNTER, R. E. \& BLANK, L. M. Pathogenicity differences of Xanthomonas malvacearum isolates. Phytopathology 44: 322, 1954 (Abstract).

HUNTER, R. E.; BRINKERHOFF, L. A. \& BIRD, L. S. The development of a set of Upland cotton lines for differentiating races of Xanthomonas malvacearum,Phytophatology 58: 830-832, 1968.

MILLER, J...W. Race builing of Xanthomonas malvacearum on cotton in Southeast Missouri. Pl. Dis: Reptr. 52: 739-740, 1968.

NAYUDU, M. V. Variation in Xanthomonas malvacearum. Indian Cott. Grow. Rev. $18(6): 350-355,1964$. 
SCHNATHORST, W. C. Altered host specificity in race 1 of Xanthomonas malvacearum by passage through a resistant variety of Gossypium hirsutum. Phytopathology 60: 258-260, 1970.

: HALISKY, P. M. \& MARTIN, R. D. History distribution, races and disease cycle of Xanthomonas malvacearum in California. Pl. Dis. Reptr. 44: 603-608, 1960.

SMITH, T. E. A variant culture of Xanthomonas malvacearum obtained from weeds roots. Phytopathology 52: 1313-1314, 1962.

VERMA, J. P. \& SING, R. P. Two new races of Xanthomonas malvacearum, the cause of blackarm of cotton. Cott. Grow. Rev. 47: 203-205, 1970. 
Composto e impresso nas oficinas graficas da E D T T RA TRA NCISCA NA Do Lar Franciscano de Menores de Piracicaba PIRACICABA - SP 